DL, Lempp H. Improving medication adherence in rheumatoid arthritis (RA): a pilot study. Psychol Health Med. 2015;20(7):781-9.

Disclosure of Interest: None declared

DOI: 10.1136/annrheumdis-2017-eular.2837

\section{AB0194 JOURNEY OF A PATIENT WITH RHEUMATOID ARTHRITIS: DELAY IN DIAGNOSIS AND TREATMENT}

A. Luissi, J.E. Rosa, F. Vergara, F.S. Pierini, M. Scolnik, M.V. Garcia, E.R. Soriano. Rheumatology section, Medical Services, Hospital Italiano de Buenos Aires, Buenos Aires, Argentina

Background: It has been shown that there is a window of opportunity for treatment in Rheumatoid Arthritis (RA). Several Argentinean studies showed an average of 8 months to arrive to a rheumatology visit and 12 months to receive DMARDs. There aren't recent studies.

Objectives: To establish delay time from onset of rheumatoid arthritis (RA) symptoms to the first rheumatology visit, to diagnosis of the disease and to the beginning of treatment with DMARDs; and to assess impact of such delay on structural damage, in a cohort of RA patients.

Methods: A retrospective study was performed including all patients with RA (fulfilling ACR/EULAR 2010 criteria) seen at a Prepaid Medical Health Plan between 2002-2015. Diagnosis delay and its impact on functional capacity measured by HAQ-A and structural damage by Sharp van der Hejde score (SvdH) was estimated. Demographic and clinical data, and dates ofdiagnosis, onset of symptoms and HAQ-A were extracted from electronic medical records. Svdh score was performed by an experienced rheumatologist.

Results: 246 patients (mean age at diagnosis 67.25 \pm 14 years, 199 (81\%) female) were included. Clinical presentation was poliarticularin $49 \%$ of the cases, oligoarticularin $47 \%$ and monoarticular in 3\%. $79 \%$ had high titers of anti-cyclic citrullinated peptide antibodies, $12 \%$ low titers, and $9 \%$ were negative. Rheumatoid factor was positive in $82.5 \%$. Mean time of follow up was 7 years (SD: 3.8 ). At the end of the follow-up, median HAQ-A $(n=145)$ was 0.125 (IRQ: $0-0.87)$. Hands and feet lastxray available were analized in 171 patients. Median Svdh score was 15 (IQR: 6-33). 242 patients (98.4\%) received DMARDs as initial treatment: methotrexate monotherapy (76\%) was the most frequent one. 41 patients (17\%) received biological agents at some point of their disease. Table 1 shows different delay times in accessing rheumatology consultation, diagnosis and beginning of treatment.

At the end of follow up, 21 patients (12.28\%) had noradiological damage (Svdh score $=0$ ). In the ROC curve (AUC $0.57,95 \% \mathrm{Cl}: 0.45-0.69$ ), 5.6 months of diagnosis delay was the best cut off valueto discriminate the presence of erosions (SvdH erosions score $>0$ ), with a sensitivity and specificity of $54.17 \%$ and $61.90 \%$, respectively. Delay in diagnosis greater than 12 months $(n=70)$ was associated with significantly radiological damage: Svdh mean 30.91 (IC 95\% 21.99-39.79) vs 21.32 (IC 95\% 16.93-25.72); $p=0.0325$.

Table 1. different delay times

\begin{tabular}{lcc}
\hline Variable & Mean (SD) & Median (IQR) \\
\hline Time from first symptoms to first rheumatology visit (months) & $9.21(20.50)$ & $3(1-7)$ \\
Time from first symptoms to diagnosis (months) & $14.2(24)$ & $4.8(2.4-13)$ \\
Time fromfirst symptoms to DMARDs indication (months) & $16.9(25.4)$ & $7(3-17)$ \\
Time from first symptoms to biological indication (years) & $6.2(4.8)$ & $5.7(2.4-7.2)$ \\
\hline
\end{tabular}

Conclusions: In a Prepaid Medical Health Planwith ease of referral, there is still a significant delay in diagnosis and treatment of RA patients.Delay in diagnosis greater than 12 months was associated with more radiological damage.

Disclosure of Interest: None declared

DOI: 10.1136/annrheumdis-2017-eular.2967

\section{AB0195 IS THERE AN ASSOCIATION BETWEEN PERIODONTITIS AND LEVELS OF ANTI-CITRULLINATED PEPTIDES ANTIBODIES IN RHEUMATOID ARTHRITIS?}

B. Rodríguez-Lozano ${ }^{1}$, J. González Febles ${ }^{2}$, F. Sánchez Alonso ${ }^{3}$, J.L. Garnier Rodríguez $^{4}$, S. Dadlani ${ }^{4}$, Y. Barrios ${ }^{5}$, M. Sanz Alonso ${ }^{6}$, F. Díaz González ${ }^{1}$. ${ }^{1}$ Rheumatology, Hospital Universitario de Canarias, Tenerife, ${ }^{2}$ Periodontology, UCM, Madrid; ${ }^{3}$ Research Unit, Sociedad Española de Reumatología, Madrid;

${ }^{4}$ Odontology/Periodontology, Dental Clinic Dr Garnier, S/C Tenerife;

5 Immunology Unit. Central Laboratory, Hospital Universitario de Canarias, Tenerife; ${ }^{6}$ Periodontology, UCM, Madrid, Spain

Background: Positivity of anti-citrullinated peptides antibodies (ACPA) indicates severity in Rheumatoid Arthritis (RA). There is evidence for chronic periodontitis (PD) in RA autoimmune response by periodontopathogenic bacteria such as P.gingivalis, through citrullination of $\mathrm{L}$-arginine.

Objectives: 1.To determine whether there is an association between PD and its severity with $\mathrm{ACPA}(+)$.2.To assess relationship between PD and ACPA titres.3.To identify association between certain periodontal parameters and ACPA titres and their possible cutoff points.

Methods: Observational, cross-sectional study RA patients $>18$ with $>4$ teeth, no tooth cleaning, antibiotic intake 6 months before.Socio-demographic and anthropometric variables, annual dental prophylaxis and comorbidities.Serum
ACPA detection:Ab lgG against CCP2 (ELISA)Eurodiagnostica:positive $>25$; ACPA titres stratification:Low (25-75), moderate (76-300) and high $(>300)$. Periodontal parameters: plaque index ( $\mathrm{PI})$, bleeding on probing (Bop), probing pocket depth,clinical attachment level (CAL). CAL loss was categorized according to European Workshop 2005 (Tonetti):T level0 (absence), TL1 (mild), TL2 (severe). Statistical analysis:t-student, Kruskal Wallis, Chi- squared tests by Stata program 13.1.

Results: 187 RA patients included (table 1),ACPA determined in 168 patients: $67.86 \%(+)$ with similar titres distribution: low $18 \%$, moderate $26 \%$, high $23 \%$. PD:182 patients (97.3\%):TL1 52.4\%,TL2 44.9\%. Although prevalence of severe $\mathrm{PD} / \mathrm{ACPA}(+)$ was higher compared to PD/ACPA(-) $(69.2 \%$ vs $30.7 \%)$, there was no association between PD and ACPA positivity/titres. Regarding the association with periodontal parameters, there was tendency of association between ACPA $(+)$ and number of periodontal pockets $\geq 5 \mathrm{~mm}$ (NPP), OR $1.02(95 \% \mathrm{Cl} 0.9-1.04)$ adjusted. There was a gradient effect, where NPP increased as ACPA titles increased, which was significant for high ACPA titres $(p \leq 0.05$,OR $1.0395 \% \mathrm{Cl}$ $1.0-1.05)$. When $\mathrm{ACPA}(+)$ was related to $\% \mathrm{PI}$ and $\mathrm{BoP}$, a strong association was observed for $\mathrm{PI}, \mathrm{OR} 10.32(\mathrm{p}<0,026)$, and only a tendency for BoP $(\mathrm{p}<0.062)$. With cutoff points of $8 \% \mathrm{PI}$ and $65 \% \mathrm{BoP}$, a risk for $\mathrm{ACPA}(+)$ was detected with an OR 2.19 and OR 2.45, respectively.

Table 1

\begin{tabular}{lcc}
\hline & $\mathrm{RA}(\mathrm{N})$ & $\mathrm{RA}(\%)$ \\
\hline Female sex & 147 & 78.6 \\
Mean age (SD) & $54.4(10.8)$ & \\
Follow up time, median (SD), years & $8.88(7.32)$ & \\
Early RA & 35 & 18.7 \\
Rheumatoid factor, seropositive & 138 & 74.2 \\
Disease Activity Ranges & & \\
$\quad$ Remission & 39 & 20.9 \\
$\quad$ Low & 45 & 24.1 \\
Moderate & 85 & 45.4 \\
$\quad$ High & 18 & 9.6 \\
Medication RA & & \\
$\quad$ Without Treatment & 10 & 5.3 \\
$\quad$ DMARDs & 99 & 52.9 \\
22 DMARDs & 22 & 11.8 \\
Biologic Drugs & 56 & 29.9 \\
\hline
\end{tabular}

Conclusions: 1 .Despite higher prevalence of severe PD in $A C P A(+)$ patients, we found no association between the presence of PD and ACPA positivity nor with serum titres. 2. On analysis of ACPA titres in relation to the severity of the periodontal parameters, there was a "gradient" risk, where NPP increased as ACPA titres increased, which was significant for high ACPA titres.3. Risk cutoff points for $\mathrm{ACPA}(+)$ were $8 \%$ for $\mathrm{PI}$ and $65 \%$ for BoP.

Disclosure of Interest: None declared

DOI: 10.1136/annrheumdis-2017-eular.4420

\section{AB0196 VASCULAR ENDOTHELIAL GROWTH FACTOR IN PATIENTS WITH RHEUMATOID ARTHRITIS}

B. Rebrov ${ }^{1}$, E. Komarova ${ }^{1}$, A. Blagodarenko ${ }^{1}$, G. Belkina ${ }^{2}$, I. Pokryshka ${ }^{3}$. ${ }^{1}$ Internal Medcine; ${ }^{2}$ Medical Chemistry, SI "Lugansk State Medical University";

${ }^{3}$ Rheumatology, Lugansk Clinical Regional Hospital, Lugansk, Ukraine

Background: The level of vascular endothelial growth factor (VEGF) may reflect the intensity of angiogenesis, which is an important step in the initiation and development of chronic rheumatoid arthritis (RA).

Objectives: to study features of VEGF level changes in the blood of RA patients, depending on the duration of the disease, the degree of activity, the level of antibodies to cyclic citrullinated peptide (anti-CCP)

Methods: 194 patients were examined with a diagnosis of RA (verified according to criteria ACR/EULAR 2010), without concomitant pathology. Among the examined patients with RA women predominated $168(86.6 \%)$, and there were 26 men (13.4\%). The age of patients was 22 to 65 years (mean age $47,7 \pm 10,22$ years), mean duration of the disease was $3,82 \pm 3,43$ years. Assessment of RA activity was done by DAS 28 index, using blood CRP in the formula. 152 patients were positive for the presence of anti-CCP ( $\geq 20 \mathrm{U} / \mathrm{ml})(78 \%)$ and $42(22 \%)$ - negative. Serum CRP concentrations (Vector-Best, Russia), anti-CCP (Orgentec, Germany), VEGF (BCM Diagnostic, Canada) were determined by ELISA. Statistical processing of the data was performed using non-parametric methods, univariate (ANOVA) variance analysis on a personal computer using a licensed software packages ("Microsoft-Excel" and "Statistica-Stat-Soft", USA)

Results: Analysis of VEGF level changes in the blood depending on the duration of $R A$ revealed that the measure was high in patients with small diseases duration 0-23 months $(472.96(341.1 ; 582.1) \mathrm{pg} / \mathrm{ml})$ compared with the group 5 years (324.1 $(199.2 ; 556.2) \mathrm{pg} / \mathrm{ml})(\mathrm{p}<0,04)$. Analysis of VEGF level in blood depending on the degree of RA activity showed that the VEGF concentration in blood increased with increasing degree of RA activity and it was the greatest - 564.4 $(340.1 ; 758.4) \mathrm{pg} / \mathrm{ml}$ in the group with a high degree (DAS28 >5.2) compared to the minimum (DAS28 $\leq 3,2)-230,5(178,1 ; 385,3) \mathrm{pg} / \mathrm{ml}$, and moderate (DAS28 $3,3-5,2)-356,4$ (278 9;553.1) pg/ml, ( $<<0,001 ; p=0,005$, respectively). Using ANOVA variance analysis, it was found that the degree of RA activity influenced the VEGF levels in the blood ( $K W=17,37 ; p<0,001)$.

Analysis of the VEGF levels in the blood depending on the level of anti-CCP 